\title{
Optics education in an optometric setting
}

\section{Vasudevan Lakshminarayanan, Aparna Raghuram}

Vasudevan Lakshminarayanan, Aparna Raghuram, "Optics education in an optometric setting," Proc. SPIE 9663, Eighth International Topical Meeting on Education and Training in Optics and Photonics, 96630P (6 October 2003); doi: $10.1117 / 12.2208382$

SPIE Event: Eighth International Topical Meeting on Education and Training in Optics and Photonics, 2003, Tucson, Arizona, United States 


\title{
Optics education in an optometric setting
}

\author{
Vasudevan Lakshminarayanan and Aparna Raghuram \\ College of Optometry, University of Missouri-St. Louis, 8001 Natural Bridge Road, Saint Louis, MO 63121-4499 \\ telephone: 314-516-6533; fax: 314-516-6712; e-mail: vengu@umsl.edu
}

\begin{abstract}
We discuss optics education within the context of an Optometric professional program leading to a degree of Doctor of Optometry (O.D.). Basic course work in Geometric, Physical, Ophthalmic and Visual Optics will be described and we will discuss how basic optical phenomena can be made relevant to the Optometric student with different academic backgrounds.

(C2003 Optical Society of America
\end{abstract}

OCIS codes: (000.2060) Education; (000.1430) Biology and medicine

Optics (geometric, physical and physiological) is an integral part of the basic science portion of an Optometric curriculum. All students in professional courses leading to the degree of Doctor of Optometry (O.D.) in north American Universities undergo a rigorous program of study stressing basic health sciences and optical sciences.

In general the optometric student population takes a semester of geometric optics, followed by a second semester of physical optics (including photometry) in their first year of the four year program of study for the OD degree. Concurrently or later they also take semester (or more) long courses in Ophthalmic optics, visual optics, environmental optics and other applied areas of optics (e.g., lighting). Their second and succeeding year courses build up on the foundation and covers vision science/physiological optics.

One of the most important factors in teaching in such a program is to make the fundamental optical science relevant to the future eye-care professional. One should also take into account the fact that the students (who in general usually have undergraduate degrees in the biological sciences) have varying abilities in mathematics and physics, even though two semesters of basic physics and a semester of calculus is a minimum pre-requisite (in most Schools and Colleges of Optometry) for application to the professional program.

Additionally, certain topical areas which are only covered briefly (if at all) in the traditional undergraduate physics/engineering optics courses such as spherocylindrical lenses, addition of obliquely crossed spherocylinders, the CIE $\mathrm{V}_{\lambda}$ curve will have to be taught in such a curriculum. Also to be taught are the optics of ophthalmic devices, ophthalmic materials and so forth. It is also important to illustrate how these topics and ideas are used in a symbiotic manner with their clinical training.

Thus, teaching optics in an optometric curriculum introduces its own set of challenges and calls for innovative teaching examples and methods. These will be described and discussed in this presentation. 